\title{
Chemical and Toxicological Evaluation of Some Snacks Consumed by Children in Egypt
}

\author{
Yousif Elhassaneen $^{1, *}$, Ryeaan Sayed ${ }^{2}$ \\ ${ }^{1}$ Nutrition and Food Science Department, Faculty of Home Economics, Minoufiya University, Shebin El-Kom, Egypt \\ ${ }^{2}$ Division of Home Economics, Faculty of Specific Education, Port Said University, Port Saied, Egypt
}

Email address:

yousif12@hotmail.com (Y. A. Elhassaneen)

\section{To cite this article:}

Yousif Elhassaneen, Ryeaan Sayed. Chemical and Toxicological Evaluation of Some Snacks Consumed by Children in Egypt. International Journal of Nutrition and Food Sciences. Vol. 4, No. 4, 2015, pp. 493-502. doi: 10.11648/j.ijnfs.20150404.22

\begin{abstract}
Snacks are commonly consumed by the most of children, that as fast foods and drinks, between main meals. Such fast foods being consumed do not usually provide a balanced meal, but they can be a useful source of some nutrients especially extra energy. The safety of snacks dietary components, including flavors and colors, is currently a subject of great interest since some of which are proved to be animal toxins and/or carcinogens. Therefore, the present work was carried out to study the chemical and toxicological evaluation of some snacks consumed by children in Egypt. Potato chips, puff snacks and fatty cake samples were purchased within about three months, transported to the laboratory, ground or homogenized before they were freeze-dried to ensure equal moisture content then used for alcohol extracts preparation. Also, extracts were prepared from potato chips samples made in lab for comparative study. Liver cells, isolated from Bolti fish and established in primary culture, were treated with a concentration of $1 \times 10^{-1}$ to $1 \times 10^{-7} \%$ snacks extracts for $48 \mathrm{hr}$. Cytotoxicity in primary cultures was evaluated by changes in lysosomes activity, mitochondrial activity and cell membrane integrity over a range of each extract concentrations. The highest adverse cytotoxic effects were recorded for puff snacks followed by fatty cake and potato chips, respectively. Very little effects induced in lab made potato chips extracts. The dose-response curves with the cytotoxicity assays corresponded well to those of adverse biochemical effects including cells growth assay and protease activity. Properties of oil extracted from tested snacks indicated that lab made potato chips extracts possessed the best quality values for AV (mg KOH/100 g oil), FFA (\% as oleic acid), PV (meg/kg oil), IN ( $\left.\mathrm{gI}_{2}\right)$ and MDA content were $0.62,0.98,6.85,112.36$ and 1.27 respectively, while as oil extracted from puff snacks registered the lowest quality values were 1.29, 2.10, 18.20, 90.24 and 3.68 respectively. For all assays, the sequence of potencies of the tested extracts was in the order of puff snacks $>$ fatty cake $>$ potato chips $>$ lab made potato chips. Our results indicate that these extracts may include chemicals which act at various sites on the liver cells to induce different cytotoxic and biochemical adverse effects.
\end{abstract}

Keywords: Potato Chips, Fatty Cake, Catfish, Primary Culture, Cytotoxicity, Biochemical Effects, Malonaldehyde

\section{Introduction}

Food is represent one of the basics for human life, therefore, quality or excellence in their food supply should be an important concern to all members of the community. Quality defines in the dictionary as a measure of excellence or a state of being free from defects, deficiencies and significant variations (http://www.businessdictionary.com). A group of activities designed to assure a standard of excellence is called quality control. Safety and wholesomeness are the most important attributes of food quality. The lack of quality as it relates to safety and wholesomeness can result in personal injury, sickness and/or death [1-2].
Among the various food groups, snacks are commonly consumed by the most of children, that as fast foods and drinks, between main meals. Such fast foods being consumed do not usually provide a balanced meal, but they can be a useful source of some nutrients especially extra energy. Snacks should be dense in essential nutrients and should not be limited to cookies, soda pop, and chips [3]. The use of additives in production and processing of snacks has increased along with the industrial development.

Food additives are used to preserve the food's taste, smell, appearance, structure and other qualities while the food is produced, worked, packed and stored [4]. The applications of the additives can be divided into several parts: colors, sweeteners, miscellaneous additives and flavorings [5]. 
Several decades ago, many studies indicated that increased consumption of the snacks rich in food additives also increased some nutritional and health problems. The nutritional problems includes magnesium deficiency with fidgeting, anxious restlessness, as well as with learning disabilities [6], the lack of an adequate high protein breakfast in school children has been linked with a poor academic performance [7], iron deficiency which is directly associated with attention deficit disorders, irritability and with poor scholastic achievement [8]; calcium deficiency with anxiety neurosis [9] and zinc deficiency with irritable, tearful, sullen, and possibly also hyperactive behavior [10]. Regarding the healthy problems, the following adverse effects have been attributed to the consumption of snacks rich in food additives: eczema, urticaria, angioedema, dermatitis, irritable bowel syndrome, nausea, vomiting, diarrhoea, depression, rhinitis, bronchospasm, migraine, sleeping problems, anaphylaxis, hyperactivity and other behavioral disorders [11-13]. With the great increase in the use of food additives, there also has emerged considerable scientific data linking food additive intolerance with various physical and mental disorders, particularly with childhood hyperactivity [14]. Additionally, in vivo and in vitro studies have been reported that some of the food additives have induced toxic, mutagenic and carcinogenic effects [15-18].

In Egypt, there has been an upward trend in consumption of snacks, in particular by children. These products contains high amount of oil and food additives. Unfortunately, there is a dearth of information concerning the quality of these foods and their effects on public health. Therefore, the present study was carried out to evaluate the chemical and toxicological properties of potato chips, puff snacks and fatty cake, a highly snacks consumed by children in Egypt.

\section{Materials and Methods}

\subsection{Materials}

\subsubsection{Market Samples}

A total of sixty samples i.e. potato chips, puff snacks and fatty cake (different brands), 20 samples per each, which represent the most common brands of snacks distributed in the Egyptian local markets, were collected at random from the Port Saied City, Port Saied Governorate, Egypt. All samples were purchased within about three months, SeptemberNovember 2014, transported to the laboratory and used for alcoholic extracts preparation.

\subsubsection{Lab-made Samples Preparation (Comparative Study)}

Fresh potato (Solauum tuberosum, L.) samples (purchased from the local markets of Port Saied City) were prepared by deep frying in palm olein (refined, bleached and deodorized palm olein, free of additives, was obtained as a donation from IFCO Misr Company, Cairo, Egypt, and used in this study because of its major commercial role in deep-fat frying) at $185 \pm 5{ }^{\circ} \mathrm{C}$ on a laboratory scale such as described by Gordon and Kourimska [19] as follow: potato were cut into slices approximately $40-50 \mathrm{~mm} \times 10 \mathrm{~mm}$ and fried in a pan filled initially with palm olein oil (4 liter). After heating the oil to $185 \pm 5{ }^{\circ} \mathrm{C}$ the potato slices were added and fried for about 10 mints. Fried potato was allowed to cool to room temperature and its alcoholic extracts were prepared for the comparative study.

\subsubsection{Food Extracts Preparation}

Market and lab-made samples were ground and freeze-dried to ensure equal moisture content then used for extraction procedure. Ground samples (100 g) were extracted with $80 \%$ aqueous ethanol $(750 \mathrm{ml})$ on an orbital shaker for $120 \mathrm{~min}$ at $70{ }^{0} \mathrm{C}$. The mixture was subsequently filtered (Whatman No. 5) on a Buchner funnel, and the filtrate was used for chemical and toxicological studies. Average values are given $\pm \mathrm{SD}$.

\subsection{Methods}

\subsubsection{Acid Value, Peroxide Value, Iodine Number, and Saponification Number}

Acid value (mg KOH / g oil), peroxide value (meq $/ \mathrm{kg}$ oil), iodine value ( $\mathrm{g}$ iodine $/ 100 \mathrm{~g}$ fat), and saponification value ( $\mathrm{mg}$ $\mathrm{KOH}$ required to saponify $1 \mathrm{~g}$ oil) were determined using the methods of the A.O.A.C. [20].

\subsubsection{Malonaldehyde Content}

Malonaldehyde content (thiobarbituric acid, T.B.A) was determined as described by Pearson [21] and Woyewoda et al., [22] as follows: A10 $\mathrm{g}$ of the sample was distilled with (47.5 $\mathrm{ml}$ of distilled water $+2.5 \mathrm{ml} \mathrm{HCI}, 4 \mathrm{~N})$ for $10 \mathrm{~min}$. A $5 \mathrm{ml}$ of the distilled water were added to $5 \mathrm{ml}$ of TBA reagent $(0.2883$ g TBA $/ 100 \mathrm{ml}$ of $90 \%$ glacial acetic acid) into Stoppard tube, and then heated in a boiling water bath 35 min. After cooling, absorbance was measured at $538 \mathrm{~nm}$ using Labo-med., Inc., spectrophotometer. The TBA value was calculated by multiplying the absorbance (ABS) by the factor (7.8). The results represented as $\mathrm{mg}$ malonaldehyde/ $\mathrm{kg}$ sample.

\subsubsection{Examination of the Alcohol Extracts Using of Fish Primary Liver Cells Cultures as an in Vitro Biological Model System}

\section{(i). Fish for Liver Cell Culture}

Bolti fish (Tilipia nilotica), one-year age, were collected from the Nile River, Egypt by arrangement with some fisherman's and transported to the laboratory in 10-gallon plastic trash cans. Fish were held outside the laboratory in 20-liter sinks including Nile River water with two aerators pushed oxygen at a flow rate of $1 \mathrm{~L} / \mathrm{min}$. Fish were fed a daily ration of $2 \%$ of their body weight/day (Basic Flake, Aquarium design, Union City, CA, USA) and the amount adjusted every two weeks. The water temperature adjusted in the range 18-25 ${ }^{0} \mathrm{C}$ by using a heating system inside the Aquarius. The photoperiod was 14-h light and 10-h dark. No diseases were observed in experimental fish.

\section{(ii). Preparation of the Primary Liver Cell Culture Model}

Bolti fish (Tilapia nilotica) liver cells were isolated according to the method mentioned by Elhassaneen [23] with 
some few modifications. Briefly, Bolti fishes were anesthetized in tricaine methanesulfonate (MS-222; Sigma Chemical Co., St. Louis, MO) and weight, length, and sex was recorded. Livers were excised to a $60 \times 15 \mathrm{~mm}$ petri dish (Baxter Healthcare Corp., McGaw Park, IL) containing Hank's Balanced Salt Solution (HBSS; Sigma Chemical Co.). Other tissues unless livers were cut away and the HBSS were removed. The livers were minced with a sterilize scissors and resuspended in $0.25 \%$ trypsin- $0.02 \%$ EDTA solution (JRH Biosciences, Lenexa, KS). The suspension was then transferred using a magnetic stirrer plate for $20 \mathrm{~min}$ after which it was strained through three layers of sterile cheesecloth to remove large tissue fragments. The cell solution was mixed with RPMI-1640 (Sigma Chemical Co.) adjusted to $330 \mathrm{mOs} / \mathrm{kg}$ and supplemented with $25 \mathrm{mM}$ HEPES buffer, $2 \mathrm{mM} \mathrm{L}(+)$ glutamine, $100 \mathrm{IU} / \mathrm{ml}$ penicillin, $100 \mu \mathrm{g} / \mathrm{ml}$ streptomycin and $10 \%$ fetal Calf serum (FCS; all from Sigma Chemical Co.) at $2000 \mathrm{rpm}$ for $5 \mathrm{~min}$. The supernatant was discarded and the cell pellet was washed twice with HBSS before counting. Cell pellet were resuspended in $10 \% \mathrm{FCS} / \mathrm{RPMI}-1640$, stained with $0.4 \%$ trypan blue stain (GIBCO Laboratories, Grand Island, NY) and were counted using a hemocytometer (Baxter Healthcare Corp.).

\section{(iii). Toxicological Experiment Design}

Five tenfold dilution of each snack's extract will be done in FCS/RPMI-1640 medium (1 ml was made for each dilution). Five 96 well flat bottom tissue culture plates (for all toxicological and biochemical assays) were set up for each tested extract as follow: for media control, $200 \mu \mathrm{l}$ of FCS/RPMI-1640 medium were added; for cell control, $100 \mu \mathrm{l}$ of cell suspension $\left(1 \times 10^{5}\right.$ cells $)$ plus $100 \mu \mathrm{l}$ of FCS/RPMI-1640 medium were added; and for tested extracts, $100 \mu$ of cell suspension ( $1 \times 10^{5}$ cells) plus $100 \mu$ of extract dilution were added to each well. After 5 days of incubation at $27{ }^{\circ} \mathrm{C}$ ( $5 \% \mathrm{CO}_{2}$ tension), all plates were removed from the incubator into laminar flow hood and toxicological as well as biochemical assays procedures were applied.

\section{(iv). Cytotoxicity Assays in Liver Cells}

\section{(a). Lysosomal Activity Assay}

Lysosomal activity in liver cells was determined by neutral red assay (NR) according to the method described by of Borenfreund and Puerner [24]. The medium was removed gently then, $0.2 \mathrm{ml}$ of NR stain/media (containing $50 \mu \mathrm{g}$ $\mathrm{NR} / \mathrm{ml}$ ) was added to each well. The plates were returned to the incubator for $3 \mathrm{~h}$ to allow for uptake of the stain into the lysosomes of viable uninjured cells. The stain/media were removed and the cells were washed with a mixture of $1 \%$ formaldehyde- $1 \% \mathrm{CaCl}_{2}$ about three times or until no more NR stain comes off. $0.2 \mathrm{ml}$ of a $1 \%$ acetic acid- $50 \%$ ethanol mixture was added to each well to extract the dye. Thereafter, the plates were remained still $10 \mathrm{~min}$ at room temperature and agitated briefly on a microtiter plate shaker for 15 seconds. The absorbance of the dye extracted was measured by using MR-5000 microtiter plate reader at a wavelength of $540 \mathrm{~nm}$.

\section{(b). Mitochondrial Activity Assay}

Mitochondrial activity in liver cells was determined by Methyl tetrazollium (MTT) assay according to the method described by Borenfreund et al., [25] as follow: a medium (0.1 $\mathrm{ml}$ ) was removed and $0.1 \mathrm{ml}$ of MTT-containing medium was added to each well. The plates were covered with foil and incubated at $27^{\circ} \mathrm{C}$ for $3 \mathrm{~h}$. The supernatant was removed from the wells and $0.1 \mathrm{ml}$ of a solution of $1 \mathrm{~N} \mathrm{HCl}$-isopropanol was added to extract and solubilize the formazan. The plates were standed up 10 min at room temperature and agitated briefly on a microtitre-plate shaker for 5 seconds. The optical density of the dye extracted of each well was measured by using MR-5000 microtiter plate reader at wavelength $550 \mathrm{~nm}$.

\section{(c). Cell Membrane Integrity Assay}

Cell membrane integrity in liver cells was determined by crystal violet $(\mathrm{CV})$ assay according to the method described by Saotome et al., [26] as follow: $40 \mu \mathrm{l}$ of $50 \%$ formalin were added to each well and left for one hour. The plates were rinsed under a gentle flow tap water and $200 \mu \mathrm{l}$ of crystal violet $(0.0625 \%)$ were added to each well and standed up 5 min at room temperature. The stain was removed and the plates were washed with tap and deionized water, and dried. The absorbance was measured by using microtiter plate reader MR-5000 at a wavelength of $540 \mathrm{~nm}$.

\section{(v). Biochemical Assays in Liver Cells}

\section{(a). Liver Cells Protein Assay}

Liver cells protein which represents the growth assay (GA) of cells was measured by the method of Babich and Borenfreund [27]. Hepatocyte cells $1 \times 10^{5}$ were suspended in $100 \mu 1$ medium and inoculated into wells of 96-well microtiter plate. On the second day $100 \mu$ of fresh medium unamended or amended with varied concentrations of tested toxic chemicals were added to the cells. After 24 hour of incubation, the medium was removed, the cells were washed three times in HBSS, and lysed in $50 \mu \mathrm{l}$ of $0.1 \mathrm{~N} \mathrm{NaOH}$. The plates were incubated one hour at $37^{\circ} \mathrm{C}$ and $200 \mu \mathrm{l}$ of Pierce BCA protein assay reagent were added to each well. After an additional $30 \mathrm{~min}$ of incubation at $37{ }^{\circ} \mathrm{C}$, the absorbance was measured in a microplate reader MR-5000 at $562 \mathrm{~nm}$. Serial dilutions of $200 \mu \mathrm{g} / \mathrm{ml}$ BSA solution in RPMI-1640 complete medium were used for protein standard.

\section{(b). Protease Activity Assay}

Protease activity (PA) assay which represents the immunological activity in liver cells was determined according to the method of Rinderrnecitt et al., [28] with some modifications. In brief, hepatocyte cells $1 \times 10^{5}$ were suspended in $100 \mu \mathrm{l}$ medium and inoculated into wells of 96-well microtiter plate. On the second day, $100 \mu$ of fresh medium unamended or amended with varied concentrations of tested toxic chemicals were added to the cells. After 24 hour of incubation, the medium was removed, and the cells were washed three times in HBSS. $40 \mu \mathrm{l}$ of buffer $(150 \mathrm{mM}$ Tris base, $30 \mathrm{mM} \mathrm{CaCl}, 0.05 \%$ Brij 35) and $50 \mu$ lof protease substrate (20\% HPA, $20 \%$ sucrose, $0.05 \%$ Brij) were added to 
each well. The plates were incubated at $37{ }^{\circ} \mathrm{C}$ with continuous shaking for 2 hours. The reaction was stopped by the addition of $50 \mu \mathrm{l}$ of $10 \%$ TCA and the plates were stored at $4 \mathrm{oC}$ for about $15 \mathrm{~min}$. After spinet the plates at $8500 \mathrm{rpm}$ for $5 \mathrm{~min}$, the supernatants were transferred to new plates and the absorbance of the plates were measured in a microplate reader MR-5000 at $540 \mathrm{~nm}$. Blank wells were prepared by the same previous steps without cell addition.

\subsubsection{Statistics}

All experiments of cytotoxicity were performed at least three times, using four wells for each concentration of tested agent. Data for the dose-response cytotoxicity curves were presented as the arithmetic mean \pm SD. Comparative cytotoxicity of tested extracts i.e. the concentration of toxicant needed to reduce absorbance of the NR, MTT, CV, GA, and PA by $10 \%\left(\mathrm{NR}_{90}, \mathrm{MTT}_{90}, \mathrm{CV}_{90}, \mathrm{GA}_{90}\right.$, and $\mathrm{PA}_{90}$ values $)$ and by $50 \%\left(\mathrm{NR}_{50}, \mathrm{MTT}_{50}, \mathrm{CV}_{50}, \mathrm{GA}_{50}\right.$, and $\mathrm{PA}_{50}$ values $)$ were computed by linear regression analysis of the data as percentage of control versus the logarithmic concentration of the toxicant.

\section{Results and Discussion}

\subsection{Chemical Properties of Oil Extracted from Snacks Distributed in Egyptian Local Markets}

Data in Table (1) and Figure (1) shows the properties of oil extracted from three popular snacks distributed in Egyptian local markets i.e. puff snacks, potato chips, fatty cake as well as lab-made potato chips for comparison study. These data indicated that oil extracted from lab-made potato chips possessed the best quality values for acid value (AV, mg $\mathrm{KOH} / 100 \mathrm{~g}$ oil), free fatty acid (FFA, \% as oleic acid), peroxide value ( $\mathrm{PV}, \mathrm{meq} / \mathrm{kg}$ oil), iodine number (IN, $\mathrm{g} \mathrm{I}_{2}$ ) and malonaldehyde content (MDA, mg. $\mathrm{kg}^{-1}$ sample) were 0.62 , $0.98,6.85,112.36$ and 1.27 respectively, whileas oil extracted from puff snacks registered the lowest quality values were $1.29,2.10,18.20,90.24$ and 3.68 respectively. According to Egyptian standard specifications of potato chips (E.S: 1629/ 2005), cake (ES: 4037/ 2005) and puff snacks (ES: 1320/ 2005), oil extracted from the best of their products should have free fatty acid ( $\%$ as oleic acids) not more than $1 \%$ i.e. lower in acidity. Being in mind such aspect, it could be noticed that oil extracted from puff snacks, potato chips and fatty cake samples is considered to have a lowest quality (FFA, 2.10, 1.39 and $1.96 \%$, respectively), consequently not suitable for human consumption. In this context, Smith, [29] mentioned that as a fat or oil is used for frying potato chips, a good quality fresh has free fatty acid content of $0.05 \%$ or less. As it is heated or used, this content may increase to as high as $0.75 \%$ in a well-handled chip-processing operation, but could go as high as $7-8 \%$ if the oil is badly abused and broken down. Unfortunately, there are no limits concern the allowed level of acid value, peroxide value and malonaldehyde content for oil extracted from the studied snacks, mentioned in FAO/WHO Codex and the Egyptian Standard Specification. Consequently, it is difficult to evaluate the obtained general average of acid and peroxide values of oil extracted from snacks samples under the present study.

When fats are heated to high temperatures such in snacks frying operations, three general chemical reactions may occur simultaneously: hydrolysis, polymerization, and oxidation. Oxidation of hot frying fat is much more important and results in rancidity, which result in undesirable and/or off-flavor chips. This effect produced by thermal oxidation was characterized by an increase in the concentration of pentanal, hexanal, heptanal, octanal, nononal, 2-heptenal, and 2-octenal [30]. As fat or oil is used for frying snacks, a chemical reaction takes place resulting in the development of free fatty acids. This reaction of the fat with the moisture from the snacked products is known as hydrolysis. Much study has been made of fat hydrolysis probably because of the ease of measurement of free fatty acids, which arise from this reaction. Also, oils undergo polymerization when subjected to high temperatures for rather long periods. It is means that the union of two or more molecules of fat to form a larger molecule. Since, this union occurs at the double bond positions; it reduces their number and, therefore, lowers the degree of unsaturation of the fat. Iodine value is a measure of the unsaturation or double bonds present in oil. Therefore, as polymer formation proceeds, there is a decrease in the iodine value of the fat or oil. Thermal polymers may be toxic to animals and result in poor nutrition and growth inhibition. Van Der Heide and Van Der Veen [31] reported that toxicity of oil used for deep fat frying was related to its content of dimeric and polymeric triglycerides (DPTG), rather than to oxidized fatty acids. Soybean oil or hardened soybean oil, heated to $220{ }^{\circ} \mathrm{C}$ for 40 $\mathrm{hr}$, caused pathological changes in weaned rats includes growth retardation, decreased feed efficiency, impaired liver function, enlargement of liver and kidneys when given at a level of $20 \%$ in the feed for 14 days. Also, the same results were reported by Elhassaneen et al., [32] and Tawfik et al., [33]. Recently, there is an increasing international concern about the presence and the adverse effects of some toxic compounds such as malonaldehyde. It is formed in fresh and ready to eat foods as a consequence of oxidation of their contents of polyunsaturated fatty acids during storage, processing and cooking [32, 34]. The formation of malonaldehyde in food as the result of the preparation procedures had been studied by Elhassaneen and Twfik [35]. From this study it could be observed that the levels of this compound in fast- foods such as potato chips are in the range 5.28 to $11.5 \mathrm{mg} \cdot \mathrm{kg}^{-1}$ for samples collected from Lower and Upper Egypt Governorates. The effect of malonaldehyde on human health has been reported by many authors that is mutagenic and carcinogenic [33, 36-37]. The mutagenicity of malonaldehyde has been demonstrated by the Ames salmonella revertant procedure [38] while its carcinogenicity was observed when painted on the skin of mice [36]. Being in mind such aspects, it could be noticed that oil extracted from some popular snacks in Egyptian local markets is considered to have low levels of quality, especially with regard to the chemical criteria, consequently probably not suitable for human consumption. 
Table 1. Chemical properties of oil extracted from tested snacks.

\begin{tabular}{|c|c|c|c|c|c|}
\hline Snacks & $\begin{array}{l}\text { Acid value } \\
\left(\mathrm{AV}, \mathrm{mg} \mathrm{KOH.100g}^{-1} \text { Oil) }\right.\end{array}$ & $\begin{array}{l}\text { Free fatty acids } \\
\text { (FFA, \% oleic acid) }\end{array}$ & $\begin{array}{l}\text { Peroxide value } \\
\left(\mathrm{PV}, \text { meq.kg oil }^{-1}\right)\end{array}$ & $\begin{array}{l}\text { Iodine number } \\
\left.\text { (IN, } \mathbf{g ~ I}_{2}\right)\end{array}$ & $\begin{array}{l}\text { Malonaldehyde content } \\
\left(\text { MDA, mg.kg }{ }^{-1}\right)\end{array}$ \\
\hline Puff snacks & $1.29 \pm 0.11$ & $2.10 \pm 0.27$ & $18.20 \pm 1.98$ & $90.24 \pm 4.78$ & $3.68 \pm 0.22$ \\
\hline Fatty cake & $1.11 \pm 0.09$ & $1.96 \pm 0.19$ & $13.16 \pm 2.01$ & $94.74 \pm 6.05$ & $3.24 \pm 0.19$ \\
\hline Potato chips & $1.03 \pm 0.08$ & $1.39 \pm 0.13$ & $12.81 \pm 1.18$ & $102.56 \pm 6.34$ & $2.35 \pm 0.17$ \\
\hline Lab- made potato chips & $0.62 \pm 0.03$ & $0.68 \pm 0.07$ & $6.85 \pm 0.98$ & $112.36 \pm 3.79$ & $1.27 \pm 0.11$ \\
\hline
\end{tabular}

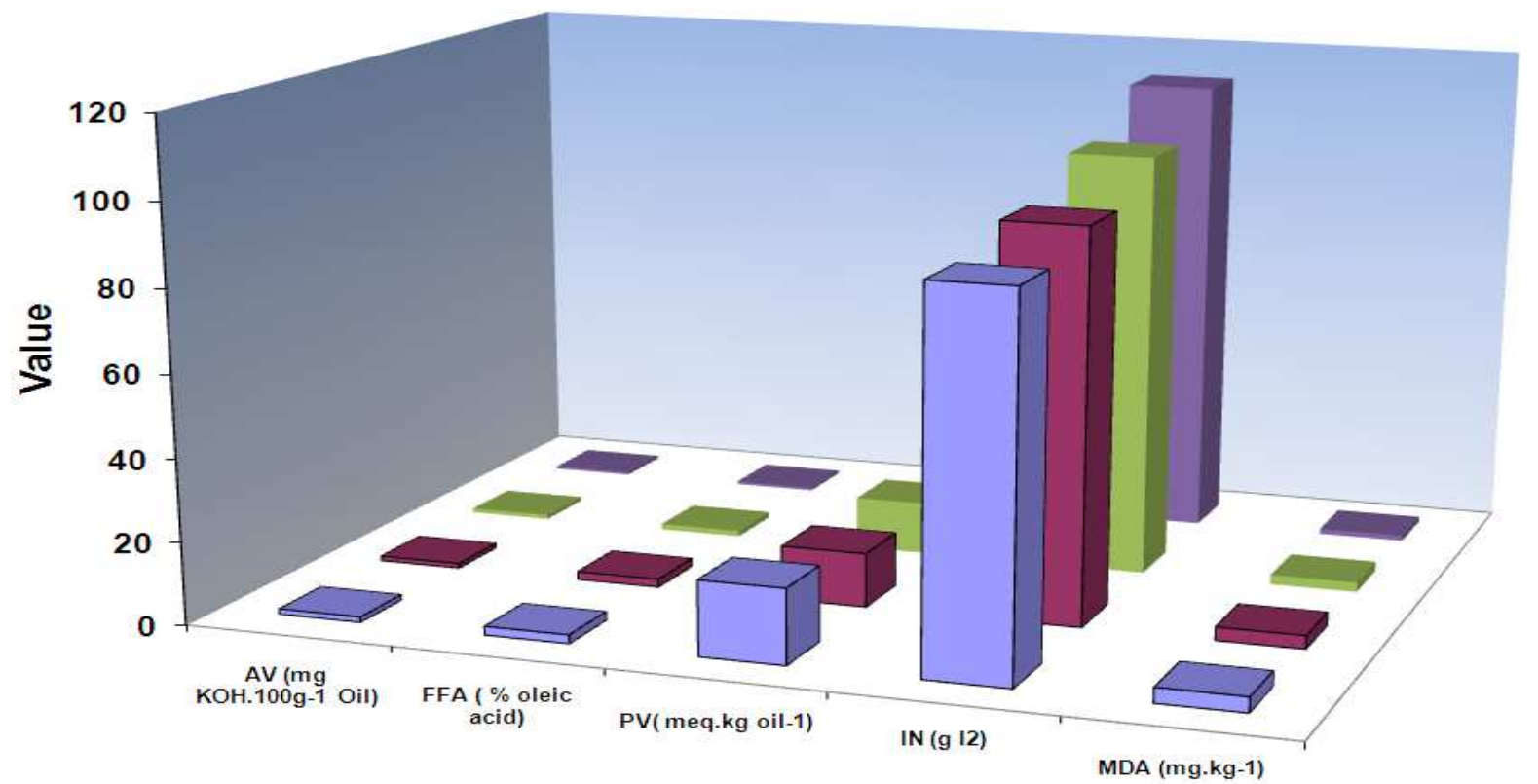

口Puff snacks $\quad$ Fatty cake $\quad$ Potato chips

Figure 1. Chemical properties of oil extracted from tested snacks

\subsection{The Adverse Effect of Tested Snacks Extracts towards Primary Culture of Isolated Fish Liver Cells}

\subsubsection{Cytotoxic Effects}

Primary liver cell cultures isolated from Bolti fish were used as an experimental tool in order to assess the adverse effects of alcoholic extracts prepared from three popular snacks distributed in Egyptian local markets i.e. puff snacks, potato chips, fatty cake as well as lab-made potato chips for comparison study. For cytotoxic effects, NR, MTT, and CV assays which determined the lysosomes activity, mitochondrial activity, and cell membrane integrity of liver cells, the data were standardized by expressing absorbance data in the presence of each extract as a percentage of that in the control medium (Figure 2). The absorbance measurements of these assays (as \% of control) were 14.27-107.03, 30.61104.34, 24.73-111.16 and 43.76-113.54 (for NR); 26.45-110.09, 40.78-109.10, 32.16-124.73 and 96.89-134 (for MTT); 26.15-116.03, 41.89-100.34, 37.73-104.11 and 55.98-109.34 and 29.89, 43.98- 105.36, 40.67-109.31 and 58.83-112.81 (for CV) for the extracts of puff snacks, potato chips, fatty cake and lab-made potato chips, respectively. The highest adverse cytotoxic effects were recorded for puff snacks followed by fatty cake and potato chips, respectively. Very little effects induced in lab made potato chips extracts.
Our similar studies indicated that some cytotoxic effects such lysosomes (NR assay) and mitochondria (MTT assay) dysfunction as well as cell wall membrane integrity (CV assay) were observed on the primary liver cells at the lower concentrations of PAH extracts of two deep-fat frying popular Egyptian foods i.e potato chips and tamiya and grilled fish [39-40]. Also, data of the present study are in accordance with that obtained by Ahmed, [18]. It was reported that highest in vitro cytotoxic effects were recorded for synthetic additives extracted from snacks including karate, loleta and potato chips, while very little effects induced by natural additives extracted from curcumin and beet roods.

\subsubsection{Adverse Biochemical Effects}

The influence of the four tested extracts prepared from puff snacks, potato chips, fatty cake as well as lab-made potato chips on the growth assay (GA) and protease activity (PA), used as immunological indicator dysfunction, of liver cells were determined in a trial to make a comparison between some cytotoxic and biochemical assays. Such as shown in Figure (3) the absorbance measurements of these assays (as a percent of control) were $32.78-123.45,49.12-100.23$, 43.09-112.34 and 62.22-111.00; and 40.44-106.34, 43.78-111.44, 52.78-100.56 and 64.34-116.45for puff snacks, fatty cake, potato chips and lab-made potato chips extracts, 
respectively. Such data indicated that the highest adverse biochemical effects were recorded for puff snacks extracts followed by fatty cake and potato chips, respectively. The lab-made chips extracts induced very little effects for these biochemical assays. The present data demonstrated that the dose-response curves with the NR, MTT and CV assays corresponded well to those with GA and PA assays. Our similar studies indicated that some adverse biochemical effects include decreasing in protein synthesis (GA) and immunological defense system (PA) were observed on the primary liver cells at the lower concentrations of PAH extracts of two deep-fat frying popular Egyptian foods i.e potato chips and tamiya and grilled fish [39-40]. Also, data of the present study are in accordance with that obtained by Ahmed, [18]. It was reported that highest in vitro adverse biochemical effects were recorded for synthetic additives extracted from snacks including karate, loleta and potato chips, while very little effects induced by natural additives extracted from curcumin and beet roods.

\subsubsection{Initial and Midpoint Toxicity of the Tested Snacks Extracts Towards Primary Culture of Isolated Fish Liver Cells}

To analyze the cytotoxicity and adverse biochemical data it was necessary to determine the exposure concentration to the tested food extracts causing initial toxicity $\left(\mathrm{NR}_{90}, \mathrm{MTT}_{90}\right.$, $\mathrm{CV}_{90}, \mathrm{GA}_{90}$, and $\mathrm{PA}_{90}$ values) and those causing midpoint toxicity $\left(\mathrm{NR}_{50}, \mathrm{MTT}_{50}, \mathrm{CV}_{50}, \mathrm{GA}_{50}\right.$ and $\mathrm{PA}_{50}$ values). Such data (Table 2) were necessary to distinguish and/or for comparison amongst the all tested extracts. For example, the midpoint cytotoxicity and adverse biochemical values for puff snacks extract were recorded lowest values for NR, MTT, CV, GA and PA followed by fatty cake and potato chips extracts. The lab-made chips extracts no recorded values i.e. out of the curve dimensional for the almost cytotoxic and biochemical assays. According to these data, the sequence of tested extracts for the all different cytotoxicity and adverse biochemical assays was in the order of puff snacks $>$ fatty cake $>$ potato chips while lab made potato chips extract recorded very little or no effects. In similar studies, Elhassaneen, [40] found that polycyclic aromatic hydrocarbons extracts of two deep-fat frying popular Egyptian foods i.e potato chips and tamiya recorded low values for the midpoint cyctotoxicity assays NR, MTT, GA, CV and PA. Also, Ahmed, [18] reported that the midpoint cytotoxicity value for synthetic additives extracted from market's snacks was recorded lowest values for all cyctotoxicity assays (NR, MTT, CV, GA and PA) while natural additives extracts of curcumin and beet roods no recorded.

Two decades ago, a protocol was developed in our laboratory to isolate hepatocytes from fish (Bolti, Tilipia nilotica), which represent one of the most common fish species cultured in Egypt. This model of cells possess obvious advantages over whole organism like attach to each other and to the culture substrate, survive for relatively extended periods of time (more than 9 days), proliferated forming confluent monolayer, diversity of origin, ability to screen large numbers of samples and low cost. Our previous studies indicated that this primary culture of liver cells used successively as a new biological model system in many food toxicological applications and cancer research [23, 40- 42]. In a trial to open a new avenue in the field of food toxicology, in this paper, the researcher intend to study the possibility of using this model of cells as an experimental tool in detection the potential toxicological effects of extracts prepared from some popular snacks distributed in Egyptian local markets.

Cytotoxicity is considered primarily as the potential of a compound to induce cell death. Most in vitro cytotoxicity tests measure necrosis. However, an equally important mechanism of cell death is apoptosis, which requires different methods for its evaluation. Furthermore, detailed studies on dose and time dependence of toxic effects to cells, together with the observation of effects on the cell cycle and their reversibility, can provide valuable information about mechanisms and type of toxicity, including necrosis, apoptosis or other events. In vitro cytotoxicity tests are useful and necessary to define basal cytotoxicity, for example the intrinsic ability of a compound to cause cell death as a consequence of damage to basic cellular functions [25, 43-45].

In general, by using three cytotoxic testing i.e. NR, MTT, and $\mathrm{CV}$, and two biochemical assays i.e. GA and PA, we were able to demonstrate three different toxic responses as a consequence of exposure to extracts prepared from snacks distributed in Egyptian local markets. The first type of response was the inhibition of cell division, which characterized by stabilization or slightly increases the initial count of cultured cells even with increasing the concentration of extract. This type of response may be due to the cellular dysfunction or damage $[43,46]$. The second type of response was the cytotoxicity or cell death, which could be characterized by the decreasing of the growth assay with the increasing of the concentration of tested extracts. Previous studies demonstrated that cytotoxicity can be resulted from cells dying and/or inhibition of cell proliferation [46-49]. Hormesis represented the third response which means increasing occurs in cells number over the controls at low concentrations of the toxic substance but the toxic effect does not manifest itself until a higher critical dose level is reached [50]. All of these data are in accordance with that obtained in our previous investigations when fish isolated liver cells exposure to paper industry effluent, pesticides, and heavy metals $[23,49,51]$. 


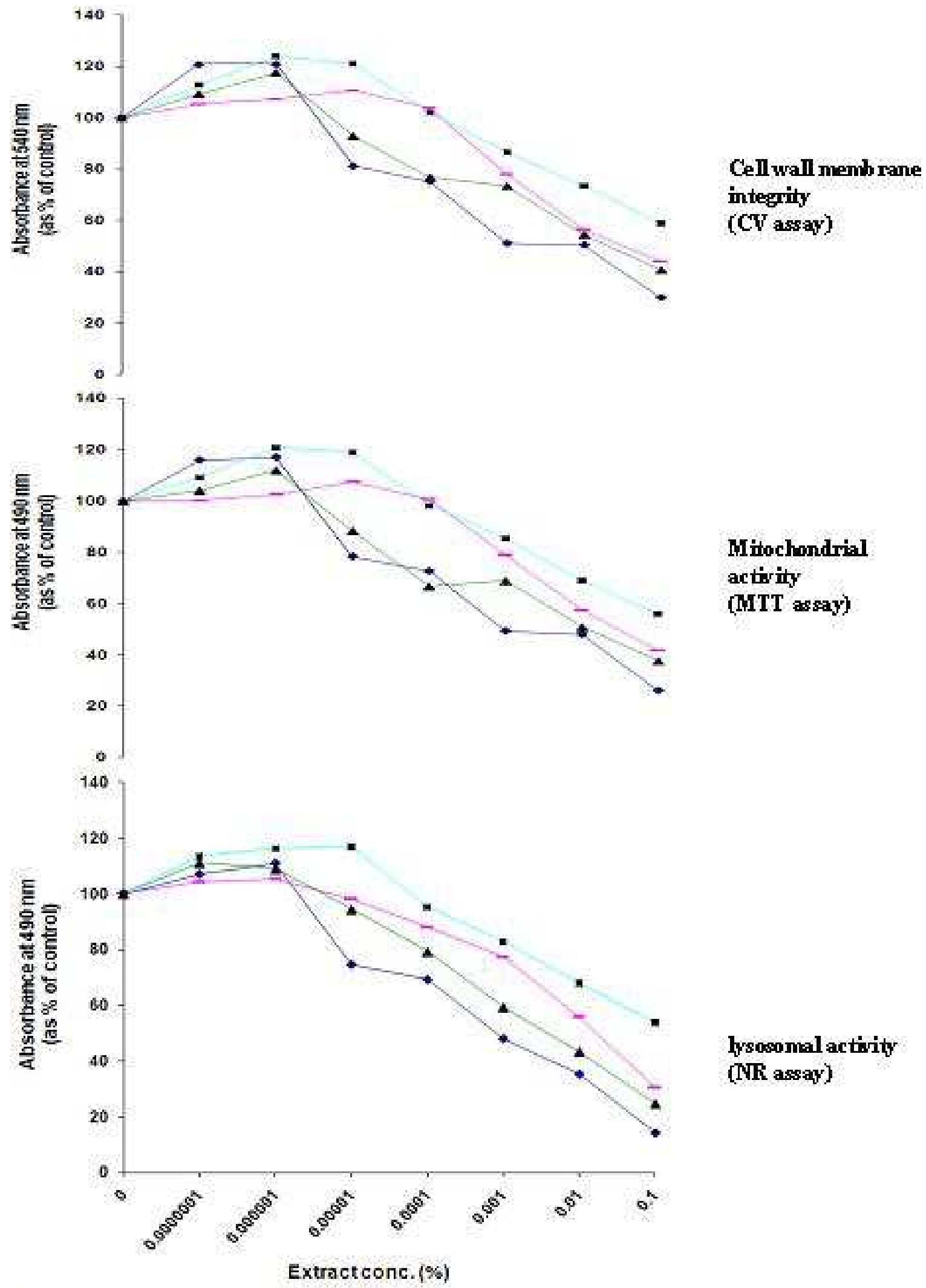

- Puff snacks - Potato chips - Fatty cake - Lab-made potato chipa

Figure 2. Cytotoxicity of snacks alcoholic extracts towards primary culture of isolated fish hepatocytes after $72 \mathrm{~h}$ of exposure at $27^{\circ} \mathrm{C}\left(5 \% \mathrm{CO} \mathrm{O}_{2}\right.$ tension). The data points are presented as the mean percent of control, with the control cultures maintained in the absence of tested snacks extracts. 


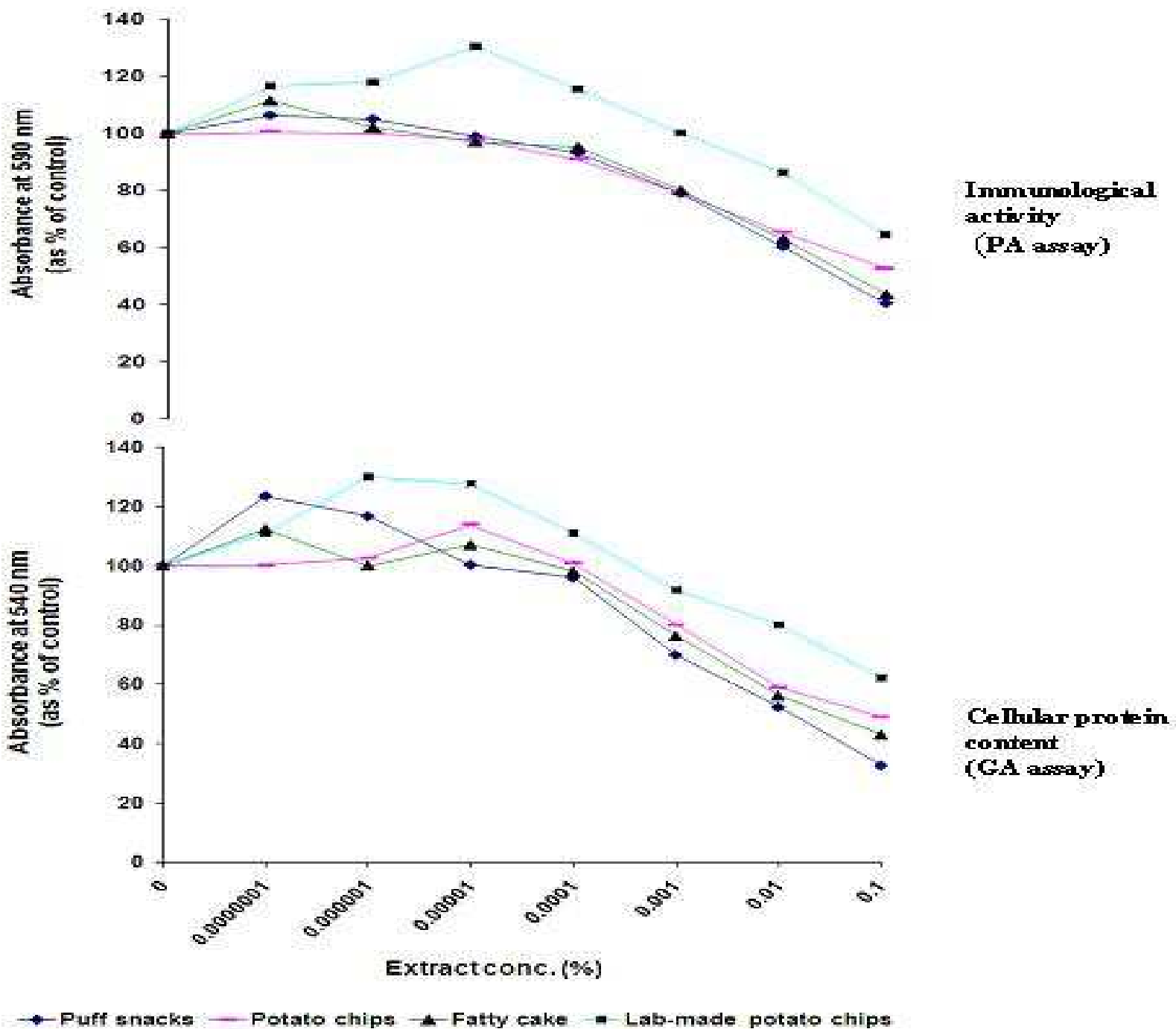

Figure 3. Adverse biochemical effects of snacks alcoholic extracts towards primary culture of isolated fish hepatocytes after $72 \mathrm{~h}$ of exposure at $27{ }^{\circ} \mathrm{C}\left(5 \% \mathrm{CO}{ }_{2}\right.$ tension). The data points are presented as the mean percent of control, with the control cultures maintained in the absence of tested snacks extracts.

Table 2. Comparative cytotoxic and adverse biochemical effects of snacks alcoholic extracts as determined by different assays.

\begin{tabular}{|c|c|c|c|c|c|c|c|c|c|c|}
\hline \multirow{2}{*}{ Snacks } & \multicolumn{2}{|l|}{ NR } & \multicolumn{2}{|l|}{ MTT } & \multicolumn{2}{|l|}{ CV } & \multicolumn{2}{|l|}{ GA } & \multicolumn{2}{|l|}{ PA } \\
\hline & $\mathrm{NR}_{90}{ }^{*}$ & $\mathrm{NR}_{\mathbf{5 0}}{ }^{*}$ & MTT $_{90}{ }^{*}$ & MTT $_{50}{ }^{*}$ & $\mathrm{CV}_{90}{ }^{*}$ & $\mathrm{CV}_{50}^{*}$ & $\mathrm{GA}_{90}{ }^{*}$ & GA $_{50}{ }^{*}$ & $\mathbf{P A}_{90}{ }^{*}$ & $\mathbf{P A}_{50}{ }^{*}$ \\
\hline Puff snacks & $1.45 \times 10^{-6}$ & $8.2 \times 10^{-4}$ & $6.4 \times 10^{-6}$ & $8.2 \times 10^{-4}$ & $8.2 \times 10^{-5}$ & $0.1 \times 10^{-1}$ & $4.6 \times 10^{-4}$ & $2.8 \times 10^{-2}$ & $4.6 \times 10^{-4}$ & $6.4 \times 10^{-2}$ \\
\hline Potato chips & $7.3 \times 10^{-5}$ & $0.1 \times 10^{-1}$ & $4.6 \times 10^{-4}$ & $4.6 \times 10^{-2}$ & $6.4 \times 10^{-4}$ & $4.6 \times 10^{-2}$ & $6.4 \times 10^{-4}$ & $1.0 \times 10^{-1}$ & $2.8 \times 10^{-4}$ & ND \\
\hline Lab- made potato chips & $4.6 \times 10^{-4}$ & ND & $6.4 \times 10^{-4}$ & ND & $8.2 \times 10^{-4}$ & ND & $2.8 \times 10^{-3}$ & ND & $8.2 \times 10^{-3}$ & ND \\
\hline
\end{tabular}

* Mean concentrations (\%) required to reduce absorbance by $10 \%\left(\mathrm{NR}_{90}, \mathrm{MTT}_{90}, \mathrm{CV}_{90}, \mathrm{GA}_{90}, \mathrm{PA}_{90}, \mathrm{GP}_{90}\right.$, and $\mathrm{CA}_{90}$, ) and by $50 \%\left(\mathrm{NR}_{50}, \mathrm{MTT}_{50}, \mathrm{CV}_{50}\right.$, $\mathrm{GA}_{50}, \mathrm{PA}_{50}, \mathrm{GP}_{50}$, and $\mathrm{CA}_{50}$ ).

\section{Conclusion}

The present study proved that, primary culture of fish liver cells can be used successively as a simple and inexpensive in vitro biological model for monitoring and/or assess the adverse effects of food pollutants. In addition to, different components formed inside the popular snacks distributed in Egyptian local markets i.e. puff snacks, potato chips and fatty cake as the result of frying/processing operations constitute really threaten to human health through inducing many cytotoxicological and adverse biochemical effects in liver cells. More research must conduct in the future in order to develop strategies for reducing the formation of these toxic compounds in foods during cooking and processing. Also, the study recommends reducing the intake of snacks such puff snacks, potato chips and fatty cake, especially in children.

\section{Acknowledgements}

This study was partially supported by the Scientific Research Unit, Post-Graduate and Research Sector, Minoufiya University, Shebin El-Kom, Egypt. 


\section{References}

[1] McCullough, M. L; Diane F.; Meir J.; Edward L.; Eric B.; Frank B.; Donna S.; David J., Graham A. and Walter C. (2002): Diet quality and major chronic disease risk in men and women: moving toward improved dietary guidance. Am J Clin Nutr, 76:1261-71.

[2] WCRFI (2014): World Cancer Research Fund International and the NCD Alliance. The link between food, nutrition, diet and non-communicable diseases, $2^{\text {nd }}$ edition October 2014, London WC1B 3HH.

[3] Badr, A. A. (2001): Biochemical and histological studies on the effect of some flavors added to baby foods and snacks in rats. Ph.D. thesis, Dept of food science. Faculty of Home economics Minoufiya University.

[4] Food Intolerance and Food Aversion (1984): A Joint Report of the Royal College of Physicians and the British Nutrition Foundation. J Royal College of Physicians of London, Vol: 18, No: 2.

[5] Wood, R.; Foster, L.; Damant, A. and Key, P. (2004): Analytical methods for food additives. Carbohydrate Polym. 58, 483-485.

[6] Durlach J. (1980): Clinical aspects of chronic magnesium deficiency. In: Magnesium in Health, Ed; MS Seeling, Spectrum Publications, New York.

[7] Connors, C.K. and Blouin, A.G. (1983): Nutritional effects on behavior of children. J Psychiatr Res, 17:193-201.

[8] Lozoff, B. and Brittenham, G.H. (1986): Behavioral aspects of iron deficiency. Prog Hematol, 14:23-53.

[9] Bryce-Smith D. (1986): Environmental and chemical influences on behavior and mentation. (John Jeyes Lecture) Chem Soc Rev, 15:93-123.

[10] [Ward, N.I.; Soulsbury, K.A.; Zeittel, V.H. and et al. (1990): The influence of the chemical additive tartazine on the zinc status of hyperactive children - A double-blind placebo-controlled study. J Nutr Med, 1: 51-57.

[11] Smith, J.M. (1991): Adverse reactions to food and drug additives. European J Clin Nutr, 45, 17-21.

[12] Ertugrul, N. (1998): Food additives regulations and health problems about upper limit of some food additives, M.S. Thesis, Istanbul University, Turkey.

[13] Aljaff, P; Banaz O. R. and Trifa A. O. (2013): A Comparison between Natural and Synthetic Food Flavoring Extracts Using Infrared Spectra and Optical Activity. Journal of Applied Physics, 5(3): 1-6.

[14] Feingold, B.F. (1973): Food additives and child development. Hospital Practice, 21, 11-12, 17-18.

[15] Wynn, M. and Wynn, A. (1981): The prevention of handicap of early pregnancy origin: Some evidence for the value of good health before conception. Foundation for Education and Research in Childbearing 9 View Road, London N6 4DJ.

[16] Miller, M. (1985): Danger Additives at Work, London Food Commission, London.

[17] Sasaki, Y.F.; Kawaguchi, S.; Kamaya, A.; Ohshita, M.; Kabasawa, K.; Iwama, K.; Taniguchi, K. and Tsuda, S. (2002):
The comet assay with 8 mouse organs: results with 39 currently used food additives. Mutat. Res. 519, 103-119.

[18] Ahmed, S. K. (2009): Biological evaluation of some food additives distributed in Egyptian local markets in vitro. M.Sc. Thesis, Faculty of Home Economics, Minoufiya University, Shebin El-Kom, Egypt.

[19] Gordon,M.H. and Kourimska,L.(1995): The effect of antioxidant on changes in oils during heating and deep frying.J.Sci.Food Agric.68:347-353.

[20] A.O.A.C. (1995). "Official Methods of the Association of Official Analytical Chemists" XX th ed. Published by the Association of Official Analytical Chemists. Arlington, Virginia, U.S.A

[21] Pearson, D. (1970): The chemical analysis of food.National college of food technology, University of Reading, Weybridge, Edit by Surry, T. and Churchill, A., Ocean fishes, Fish industry, 43, (6): 57 - 59.

[22] Woyewoda, A.D.; Shaw, S.J. Ke, P.J. and Burns, B.G. (1986): Recommended laboratory methods for assessment of fish quality.Canadian Technical Report of Fisheries and Aquatic Sciences, No. 1448: 65 - 72.

[23] Elhassaneen, Y. A. (1996): Biochemical and technological studies on pollution of fish with pesticides and polycyclic aromatic hydrocarbons. Ph.D., Dept. of Agric. Chemistry, Fac. of Agriculture, Mansoura University, Mansoura, Egypt.

[24] Borenfreund, E. and Puerner, J.A. (1984). A simple quantitative procedure using monolayer cultures for cytotoxicity assays (HTD/NR-90). J. of Tissue Culture Methods, 9: 1.

[25] Borenfreund, E.; Babich, H. and Martin-Alguachi, N. (1988): Comparisons of two in vitro cytotoxicity assays: The neutral red (NR) and Tetrazolium (MTT) tests. Toxicology in Vitro 2, $1-6$.

[26] Saotome, K.; Morita, H. and Umeda, M. (1989): Cytotoxicity test with simplified crystal violet staining method using microtitre plates and its applicability to injection drugs. Toxicol. in vitro, 3: 317-321.

[27] Babich, H. and E. Borenfreund (1987): In vitro cytotoxicity of organic pollutants to bluegill sunfish (BF-2) cells. Envir. Res. 42:299-273.

[28] Rindermecitt, H.; Geokas, M.C.; Silverman, P. and Haverback, B.J. (1968): A new ultrasensitive method for the determination of proteolytic activity. Clin. Chim. Acta, 21:197-203.

[29] Smith, O. (1957): Potatoes and N.P.C.I. Research. Natl. Potato Chip Inst., Proc. Prod. and Tech. Div. Meetings, pp. 3-5.

[30] Wilson, L.W. (1970). Investigation of the light- struck- flavor of potato chips. Diss. Abst., 31 (11): 6681.

[31] Van Der Hide, R. F., and Van Der Veen, J. (1977). Problem related to deep fat frying. Veoding, 38: 406 - 417.

[32] Elhassaneen, Y.E; H. A. El-Fadaly; and N.E. Dewan (2003): Bioremoval of toxic substances from edible oils as affected by deep-fat frying process. Pakistan J. of Biological Science, 6 (24): 1979 - 1990.

[33] Tawfik, S.S.; Fahim, H.I.; Ashour, B.M.; Elhassaneen, Y.A; and Abou Seif, H.S. (2003): Effect of fat quality and frying on growth and some Biochemical aspects in rats. Assiut Veterinary Medical Journal, 49 (97): 113 - 140. 
[34] Gray, J. I. and Morton, D.I. (1981): Some toxic compounds produced in food by cooking and processing: A review. J. Human Nutr., 35: 5-23.

[35] Elhassaneen A. Yousif ; and Tawfik, L.M. (1998). "The presence of some carcinogens in human foods distributed in Egyptian local markets. J. of Home Economics, 8 (3): 23 - 38. [ISSN 1110-2578]

[36] Shamberger, R. J.; Andreone, T. L. and Willis, C. E. (1974): Antioxidants and cancer. IV. Malonaldehyde has initiating activity as a carcinogen. J. Natr. Cancer Inst. 53: 1771.

[37] Mukai, F. H. and Goldstein, B. D. (1976): Mutagenicity of malonaldehyde, a decomposition product of peroxidized polyunsaturated fatty acids. Science, 191: 868.

[38] Shamberger, R.J.; Corlett, C.L.; Beaman, K.D. and Kasten, B.L. (1979): Antioxidants reduce the mutagenic effect of malonaldehyde and (-propiolactione. Mutat. Res. 66: 349.

[39] Elhassaneen Y. A. (1999): "Toxicological and biochemical effects of polycyclic aromatic hydrocarbon compounds produced in fish by cooking and processing". $6^{\text {th }}$ Arabic Conference on Food Science and Technology, $16-18^{\text {th }}$ march, Egyptian Society of Food Science and Technology, Cairo, Egypt, pp. $249-270$.

[40] Elhassaneen, Y. A. (2002): New and quickly biological method for detection the potential chemical toxins and/or carcinogens in foods. Proceedings of $2^{\text {nd }}$ scientific Conference on Foodborne Contamination and Egyptian's Health $(24-24$ April), Faculty of Agriculture, Mansoura University, Mansoura, Egypt, pp 371-394.

[41] El-Saadany, M.A. (2001): The effect of dietary phytochemicals on the prevention of liver cancer initiation induced by some chemical carcinogenesis. M.Sc. Thesis, Fac. of Home Economics, Minoufiya University, Shebin El-Kom, Egypt.

[42] Elhassaneen, Y. A. and Yahya A. Abd Elhady (2014): Onion peel powder alleviate acrylamide-induced cytotoxicity and immunotoxicity in liver cell culture. Life Sci J., 11(7):381-388.

[43] North-Root, H.; Yackovitch, F.; Demetrulias, J.; Gacula, M. and Heinz, J.E. (1982): Evaluation of an in vitro cell toxicity using rabbit corneal cells to predict the eye-irritation potential of surfactants. Toxicology Letters 14, 107-214.

[44] Borenfreund, E. and Puerner, J.A. (1985): Toxicity determined in vitro by morphological alterations and neutral red absorption. Toxicology Letters 24, 119-124.

[45] Valentin, I.; Lhuguenot, J.C. and Chagnon, M.C. (2000): Uridine uptake inhibition as a cytotoxicity test for a human hepatoma cell line (HepG2 cells): comparison with the neutral red assay. Biochimica Biophysica Acta 794, 373-380.

[46] Kocan, R.M.; K.M. Sabo and M.L. Landolt (1985): Cytoyoxicity/genotoxicity: the application of cell culture techniques to the measurement of marine sediment pollution. Aquatic Toxicology, 6:165-177.

[47] Balls, M. and Bridges, J.W. (1984): The FRAME research program on in vitro toxicology. In: Goldberg, A.M. (Ed.), Acute Toxicology Testing: Alternatives Approaches. Mary Ann Liebert, New York, pp. 61-80.

[48] Dierickx, P.J. (1989): Cytotoxicity testing of 114 compounds by the determination of the protein content in HepG2 cell cultures. Toxicology in Vitro 3, 189-193.

[49] Elhassaneen, Y. A.; Khater, O.M.; Tawfeek, L.M. and Sanad, M. (1997): In vitro biochemical studies on pollution of fish with paper industry effluents. Second Egyptian Conference of Home Economics (25-26 May), Faculty of Home Economics, Minufiya University, Egypt, pp. 183 - 196.

[50] Laughlin, R.B.; J. Ng and H.E. Guard (1981). Hormesis: a response to low environmental concentrations of petroleum hydrocarbons. Science, 211: 705-707.

[51] Elhassaneen, Y.A. (2001): More quickly method for determination the potential chemical toxins and/or carcinogens in the Egyptian environment. Proceedings of the 3rd International \& Trade Fair for Environmental Management and Technologies (29-31October), Ministry of state for Environmental Affairs, Cairo International Fairground, Egypt, pp. $455-455$. 